\title{
One in the Hand Worth Two in the Bush? Reproductive Effort of Young Males Is Not Affected by the Presence of Adult Males
}

\author{
Kevin L. Monteith ${ }^{1,2 *}$, Kyle B. Monteith ${ }^{2}$, Jonathan A. Jenks ${ }^{2}$ and Rhiannon P. Jakopak ${ }^{1}$ \\ ${ }^{1}$ Haub School of Environment and Natural Resources, Wyoming Cooperative Fish and Wildlife Research Unit, Department \\ of Zoology and Physiology, University of Wyoming, Laramie, WY, United States, ${ }^{2}$ Department of Natural Resource \\ Management, South Dakota State University, Brookings, SD, United States
}

OPEN ACCESS

Edited by:

Paul Richard Krausman,

University of Arizona, United States

Reviewed by:

Marco Festa-Bianchet,

Université de Sherbrooke, Canada

Francisco Garcia-Gonzalez, Estación Biológica de Doñana (EBD),

Spain

${ }^{*}$ Correspondence:

Kevin L. Monteith

kevin.monteith@uwyo.edu

Specialty section:

This article was submitted to Behavioral and Evolutionary Ecology,

a section of the journal

Frontiers in Ecology and Evolution

Received: 18 February 2020

Accepted: 31 July 2020

Published: 18 August 2020

Citation:

Monteith KL, Monteith KB, Jenks JA and Jakopak RP (2020) One in the Hand Worth Two in the Bush? Reproductive Effort of Young Males is Not Affected by the Presence of Adult Males. Front. Ecol. Evol. 8:274 doi: 10.3389/fevo.2020.00274
Reproduction is a costly endeavor, and most large, long-lived, and iteroparous mammals exhibit conservative life-history tactics wherein an individual may forego or abandon a reproduction event for the sake of survival. Nevertheless, risks and benefits associated with reproduction are not equal across males and females, nor across their life. Whereas expenditure for females is associated with rearing young (e.g., lactation), expenditure for males occurs with securing mating opportunities. Young males may be more successful when dominant males are lacking, but it is less clear whether-and at what cost-young males will expend effort when those opportunities arise. We designed an experiment to quantify reproductive effort (e.g., food intake, somatic loss [body mass and fat]) of male white-tailed deer (Odocoileus virginianus) to better understand the reproductive ecology of male ungulates, with an emphasis on determining how adult males $(\geq 4.5$ years old) affect timing and extent of reproductive effort expended by yearling males (1.5-years old). Food intake, hormone levels, body mass, and somatic loss during rut were similar between yearling males that interacted with adult males and those that did not. Somatic loss by all males was greatest during peak estrus of females, but forage intake relative to metabolic body mass for yearling males was nearly twice that of adult males. Testosterone levels were lower for yearling than adult males early in rut and were related negatively to forage intake. Whereas adult males lost $20 \%(23.5 \mathrm{~kg})$ of body mass and $31 \%$ (5.3 percentage points [ppt]) of body fat during the rut, yearling males lost $12 \%$ ( $9.3 \mathrm{~kg}$ ) of body mass and $22 \%$ (4.7 ppt) of body fat. Reproductive effort by young males was not influenced by the presence of adult males, though young males expended less reproductive effort than adults. Instead, reproductive allocation occurred in a state-dependent manner, where pre-season levels of somatic reserves dictated reproductive effort, regardless of age. Like female ungulates, male deer displayed risksensitive reproductive allocation wherein current reproductive allocation occurred as a function of resources garnered during the prior season and were expended in a way that should have avoided over-investing and creating a tradeoff between reproduction and survival.

Keywords: life-history theory, nutritional condition, Odocoileus virginianus, risk-sensitive reproductive allocation, state dependent, trade-offs, ungulates 


\section{INTRODUCTION}

Reproduction is a costly endeavor, and animals must balance the potential fitness benefits of investing energy into reproduction with other functions critical to life, such as avoiding predators, somatic growth, and maintenance (Kozłowski, 1992). The amount of energy and resources invested into reproduction is a reoccurring decision that iteroparous animals make throughout much of their life, with implications for lifetime reproductive output, individual condition, and survival (Stearns, 1992). Most large, long-lived, and iteroparous mammals exhibit conservative life-history tactics wherein an individual will either forego or withhold some degree of resources from reproduction for the sake of survival. Individuals who do not have sufficient resources to devote to reproduction are unsuccessful competitors or, in extreme cases, risk mortality (Andersson, 1994). Throughout their lives, individuals are balancing the risk of investing resources into reproduction in the near term with the potential reward of increasing fitness over the long term.

For female ungulates, reproduction is resource-intensive, and females balance risks and potential fitness benefits of reproduction in a risk-sensitive manner (Monteith et al., 2013b, 2014b; Bårdsen et al., 2014). Female ungulates exhibit a pronounced period of extensive maternal care wherein the majority of resources necessary to sustain growth and development of offspring comes from the mother (Clutton-Brock et al., 1989; Monteith et al., 2014a). This resource demand is met by drawing on somatic reserves or increasing forage intake, or some combination thereof (Jönsson, 1997; Panzacchi et al., 2010; Tollefson et al., 2010; Monteith et al., 2014b). Nevertheless, if resources are inadequate to sustain offspring growth and survival, female ungulates will withhold resources necessary to preserve their survival at the cost of their offspring (Martin and Festa-Bianchet, 2010; Shallow et al., 2015) - a concept known as risk-sensitive reproductive allocation (Bårdsen et al., 2008).

The risks and benefits associated with reproduction are not equal across males and females. Male ungulates similarly exhibit a period of extensive resource allocation; however, this expenditure typically occurs during a truncated window of time associated with the mating season (i.e., rut), except for territorial species where expenditures may occur over a longer period through territory maintenance (Mysterud et al., 2004; Corlatti et al., 2014). Nevertheless, reproductive effort among male ungulates often has been thought of in more of a riskprone manner influenced by sexual selection (Andersson, 1994). During the rut, male ungulates may expend energy to obtain or maintain status within a dominance hierarchy, retain a territory, or search for and tend receptive females, all with the underlying goal of securing mating opportunities (Mysterud et al., 2004). Reproductively active males spend more time resting and breeding and little time foraging (Willisch and Ingold, 2007). Expenditures associated with the rut can result in males losing $\geq 25 \%$ of their body mass (McElligott et al., 2003). Though mass loss associated with rut has been proposed to be largely caused by increased reproductive activity, there also is pronounced hypophagia in some males (Miquelle, 1990; Willisch and Ingold, 2007; Mysterud et al., 2008a), which is consistent with the inability of activity alone to explain patterns of mass loss (McElligott et al., 2003; Foley et al., 2018). Regardless, the substantial reproductive effort (e.g., reductions in forage intake, loss in somatic reserves) results in males exhibiting reductions in nutritional condition following the mating season (Yoccoz et al., 2002; Mysterud et al., 2003) and potentially negative effects to survival during the ensuing winter (Clutton-Brock, 1982; Stevenson and Bancroft, 1995; Ditchkoff et al., 2001). Indeed, physiological consequences of the rut have been proposed to contribute to a risky lifestyle; consequently, skewed sex ratios emerge through disproportionate mortality among males (Berger and Gompper, 1999). Nevertheless, evaluations of reproductive effort among males is underrepresented in the literature when compared with females (Bleu et al., 2016), likely because of methodological issues associated with measuring reproductive effort in males (Mysterud et al., 2004).

Reproductive costs-and the associated risks and benefitsare not static across life. Using too many resources in any single reproduction event, especially at a young age, may compromise growth and survival thereafter, which is fundamentally counter to the conservative life-history tactic possessed by most large, long-lived, iteroparous mammals (Stearns, 1992). Yet, social status might mediate the extent to which individuals expend resources in a single reproduction event. Mating success often is determined by social status, which is associated with traits such as body mass, age, size of antlers or horns, and demeanor (Townsend and Bailey, 1981; Miller et al., 1987; Kruuk et al., 2002; DeYoung et al., 2006). The presence of competitors who are larger, older, and dominant reduces the utility of younger and smaller males attempting to compete because adult males tend to dominate aggressive interactions (Mysterud et al., 2003; DeYoung et al., 2006; Willisch and Neuhaus, 2010). In other words, the domineering presence of adult males may suppress reproductive effort of young males (Miller and Marchinton, 1995). In the presence of mature males, young males are expected to reduce resources allocated to reproduction, because though they may increase current reproductive success, they may jeopardize lifetime reproductive success and overall fitness by risking injury and compromising growth and survival thereafter (Geist, 1971; Hogg and Forbes, 1997). If adult males are absent, however, it could be advantageous for young males to expend reproductive effort and participate in mating. Without having to compete with an adult male, a young male could reduce age at first reproduction, leading to increased fitness (Cole, 1954). For example, though it comes at the cost of survival, young male Soay sheep (Ovis aries) were more likely to participate in reproduction following population crashes that led to a sex ratio skewed toward females (i.e., reduced number of older males), whereas young males rarely participated in mating before the crash (Stevenson and Bancroft, 1995). Though it may be reproductively advantageous in the short term, it is unclear the level of somatic costs a young male might incur from participating in breeding at a young age and whether the social environment would alter the level of reproductive effort.

To better understand how young males navigate the relative risks and benefits of breeding at a young age, we quantified extent and timing of reproductive effort (i.e., weekly forage intake, 
change in body mass and body fat, and hormone levels; Charnov, 2002) for young and adult male white-tailed deer using a manipulative experiment. In particular, we determined the extent to which yearling males (1.5 years old) expended reproductive effort in the presence (i.e., yearlings subordinate) and absence (i.e., yearlings dominant) of adult males ( $\geq 4.5$ years old) in an experimental framework, along with assessing hormones that may mediate such processes. We evaluated hypotheses and associated predictions examining whether yearling males altered their reproductive effort based on their social environment.

We hypothesized that yearlings would vary forage intake and subsequent somatic (i.e., body mass and fat) loss based on the presence of adult males. If young males reduce participation in the rut in the presence of adult males or increase reproductive effort in their absence, we predicted higher levels of forage intake and less somatic loss of young males when adult males were present than when they were absent (Figure 1).

Second, we hypothesized that yearling males would vary in the degree to which they track timing of estrus in females according to their social status. We predicted that expenditures of young male deer would be less synchronous with estrus in females when in the presence of adult males (Figure 1). Conversely, in the absence of adult males, young male deer would better synchronize their efforts with estrus in females.

We also hypothesized that hormone levels of yearlings would vary based on whether adult males were present, providing a possible mechanism to mediate flexibility in reproductive effort in yearling males. Hormone levels of males typically increase as rut progresses and then decline post-rut (Miller et al., 1987; Newman et al., 1998; Pelletier et al., 2003; Corlatti et al., 2012). Moreover, hormone levels may be correlated with dominance rank (Pelletier et al., 2003) and forage intake (Ryg, 1982; Newman et al., 1998) and thus, suppression of yearling males by adult males should result in lower levels of serum testosterone and cortisol in young, subordinate males during the rut (Figure 1).

In contrast to the aforementioned hypotheses, reproductive allocation by males may occur in a risk-sensitive manner, much like that of females. If so, and in accordance with an hypothesis of risk-sensitive reproductive allocation, forage intake and somatic loss should be a function of the reserves a male possesses pre-rut and how the animal is currently allocating energy (i.e., growth vs. maintenance). Therefore, yearling males should exhibit higher forage intake and experience less somatic loss than adult males because they are smaller and still allocating resources to growth (Monteith et al., 2009); and consequently, the presence of adult males should not affect reproductive effort by young males. Moreover, across age classes, somatic reserves expended during the rut should be a function of reserves present at the beginning of the rut. Although this hypothesis has previously been termed the individual quality hypothesis (Pelletier et al., 2006), the term individual quality also has been used to explain a different theoretical idea (Bergeron et al., 2011). Therefore, we chose to reference the idea of state-dependent allocation to reproduction as being risk-sensitive reproductive allocation, which also is in keeping with this body of work for females (Bårdsen et al., 2008; Monteith et al., 2013b; Bårdsen et al., 2014).

\section{STUDY AREA AND METHODS}

We conducted our research at the Wildlife and Fisheries Sciences Research Facilities at South Dakota State University, Brookings, South Dakota, United States $\left(44^{\circ} 20^{\prime} \mathrm{N}, 96^{\circ} 47^{\prime} \mathrm{W}\right)$, where we managed a herd of hand-raised white-tailed deer that were accustomed to small enclosures (Delger et al., 2011; Monteith et al., 2014a, 2019). Elevation was $490 \mathrm{~m}$ above sea level and temperature in the region varied from $-29^{\circ} \mathrm{C}$ in the winter to $>38^{\circ} \mathrm{C}$ in the summer, with mean annual temperatures of $7-9^{\circ} \mathrm{C}$ (Spuhler et al., 1971). Annual precipitation generally varied from 33.0 to $63.5 \mathrm{~cm}$ with snowfall ranging from $63.5 \mathrm{~cm}$ to $114.0 \mathrm{~cm}$ (Spuhler et al., 1971).

Research animals were adult ( $\geq 4$-years old; range $=4$ 10 years old) and yearling (1.5-years old) male white-tailed deer that represented three treatment groups: adult males, dominant yearlings (adult males absent), and subordinate yearlings (adult males present). We used all yearling males available within any particular year for the study and we randomly assigned them to treatment groups. Based on assigned status, subordinate

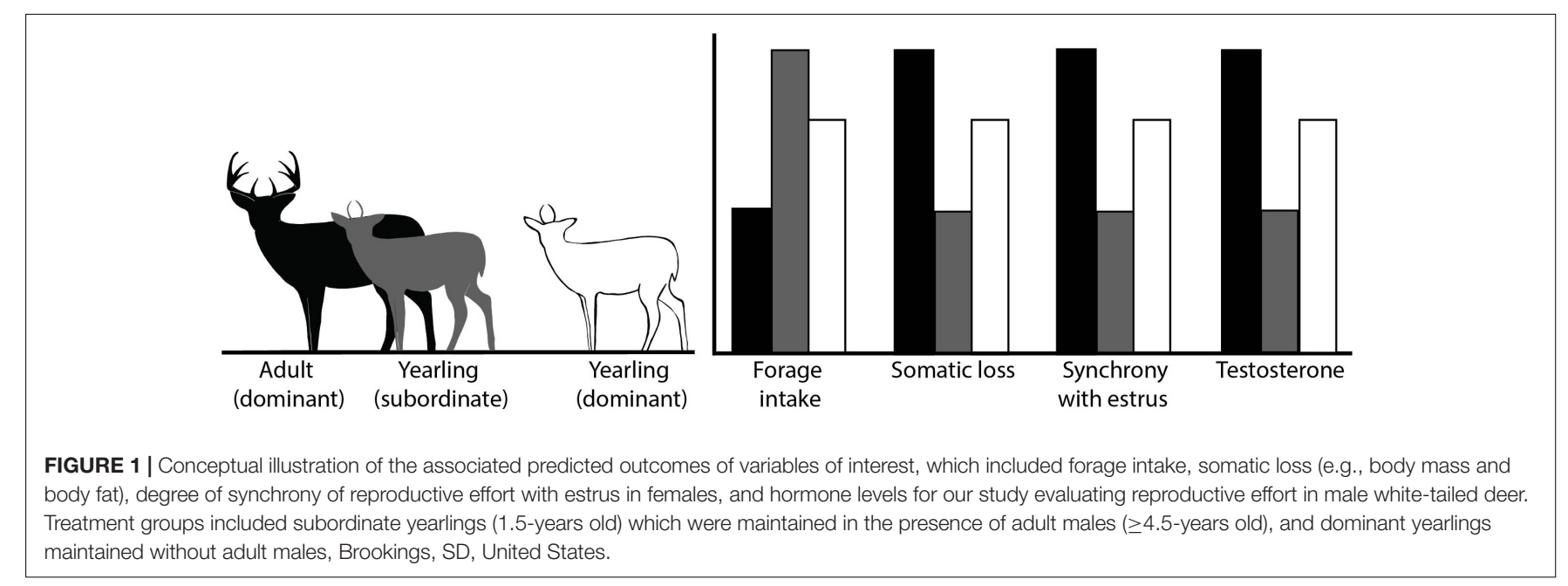


yearlings were housed and allowed to interact with adult males and females, whereas dominant yearlings were housed only with 1 other yearling male and females. Although we did not quantify dominance hierarchy among groups directly, based on daily observations of interactions between males, yearlings in the presence of adult males were clearly subordinate to those adult males. In contrast, the demeanor and level of aggression displayed by dominant yearling males in the absence of adult males was different than subordinate yearlings. Dominant yearling males frequently engaged in aggressive interactions and pursued females in their enclosure in contrast to subordinate yearlings.

Although sample size within each year varied depending upon the availability of yearling males, 1-2 dominant yearling males were housed with 1 female, and 2-3 subordinate yearlings were housed with 2-3 adult males and 2 females. Different males were used in the study each year, with the exception of 2 adult males that were used 2 years, and 3 adult males were used previously as yearling males in the study ( 2 were dominant yearlings and 1 was a subordinate). Through the remainder of the year, unless animals were used in other trials (Monteith et al., 2014a), all deer that were part of the captive herd, which ranged between 24 and 67 adult animals, were housed together in a 4-ha enclosure.

During weekly trials, males were confined to a $3.0-\mathrm{m}^{2}$ enclosure (1.22 $\mathrm{m}$ by $2.44 \mathrm{~m}$ ) with access to feed and water ad libitum without confounding competitive interactions of other individuals for forage (Monteith et al., 2014a). Designated groups were allowed to interact freely during the weekends, whereas during trials (Monday-Friday), we released males into an adjacent enclosure $\left(>280 \mathrm{~m}^{2}\right)$ for a minimum of $1 \mathrm{~h}$ each morning to allow adult and subordinate yearling males and females, or dominant yearlings and females to interact to maintain dominance hierarchies.

We conducted trials during 5 years, 2006-2008 and 20102011. We fed deer rations of shelled corn and pelleted soy hulls during 2006-2008, and switched rations in 2010-2011 to a mixed feed of shelled corn, oats, distillers grain, and pelleted soy hulls (Monteith et al., 2014a, 2019). Feed types were offered in separate containers to allow monitoring of intake rates. Shelled corn was $88 \%$ digestible with $8 \%$ crude protein content while the shelled corn, oats, and distillers grain mixture was $87 \%$ digestible with $15 \%$ protein, both of which were considered high-quality forage, whereas pelleted soy hulls were $62 \%$ digestible with $12 \%$ crude protein and were considered lower quality forage (Monteith et al., 2009, 2014a, 2019). We offered feed and water ad libitum; diets were the normal composition of feeds that animals were maintained on outside of the study similar to other captive studies involving white-tailed deer (Mautz et al., 1976).

We monitored food intake and body mass weekly beginning in mid-October for 9 weeks until mid-December to encompass the entire mating season, which typically peaks in early November for deer in the Northern Great Plains (Miller and Marchinton, 1995). We monitored feed intake for 5 days during each weekly trial. We measured daily intake rates of feed by weighing orts daily with a hanging scale accurate to $45.4 \mathrm{~g}$ (Hanson Scale Company, model 600, Shutuba, MS, United States). We collected and dried a sample of each feed to a constant weight at $50^{\circ} \mathrm{C}$ to calculate dry matter intake (Monteith et al., 2014a). We weighed deer weekly using a walk-on scale accurate to $454 \mathrm{~g}$ (Adrian J. Paul Company, Duncan, OK, United States). We then calculated daily forage intake of dry matter as a function of metabolic body mass $(\mathrm{g} / \mathrm{kg}$ $\mathrm{BM}^{0.75}$ ) per day (Robbins, 1983).

During 2006-2008 and 2010-2011, we chemically immobilized each male in mid-October to determine nutritional condition and hormone concentrations at the beginning of the rut. Nevertheless, in 2010-2011, we also immobilized males in mid-December to quantify change in nutritional condition during the rut and determine post-rut hormone levels. We chemically immobilized males by remote delivery of a combination of telazol, ketamine, and xylazine and antagonized with tolazoline (Monteith et al., 2012). While immobilized, we determined nutritional condition of each male using ultrasonography. We measured maximum depth $( \pm 0.1 \mathrm{~cm})$ of rump fat cranial to the cranial process of the tuber ischium and parallel to the spine using electronic calipers with a portable ultrasound device (Aloka 210; Aloka, Inc., Wallinford, $\mathrm{CT}$, United States) and a 5-MHz linear transducer following protocols developed for mule deer (Stephenson et al., 2002; Cook et al., 2010). Because rump fat thickness was $>0.3 \mathrm{~cm}$, body condition scores were not necessary to estimate ingesta-free body fat (Cook et al., 2007). Given their similarities in morphology and fat deposition, we assumed that equations developed to estimate ingesta-free body fat (IFBFat) for mule deer (Odocoileus hemionus) would be sufficient for white-tailed deer (Monteith et al., 2012). Therefore, we used a combination of body mass and rump fat thickness to estimate scaled IFBFat (Cook et al., 2010). We evaluated change in IFBFat proportionally, but also by the decline in percentage points (ppt), which is a representation of the amount of fat lost scaled to body size (Monteith et al., 2013b). We collected blood from immobilized deer via venipuncture of the cephalic vein, and kept samples cool until centrifugation within $6 \mathrm{~h}$ of collection and stored serum at $20^{\circ} \mathrm{C}$ until assayed. Blood serum was subsequently analyzed by chemiluminescent immunoassay for testosterone and cortisol concentration (University of Michigan MLabs, Detroit, MI, United States).

To obtain the temporal pattern of estrus cycles of female deer, we back-calculated date of estrus from date of parturition based on the average gestation length for six adult females where we observed copulation and parturition. Average date of copulation for those six females was 10 November $(S E=2.5$ days $)$, and average gestation length was 197 days ( \pm 2.4 days). For all females used during the study $(n=22)$, mean date of parturition was 27 May ( \pm 1.6 days) resulting in an average date of standing estrus of 12 November ( \pm 1.7 days, median $=14$ November), which indicated that $86 \%$ of mating occurred during weeks $45-47$.

During the remainder of each year, animals were confined to various pens within the 4-ha enclosure and had access to shelled corn or the shelled corn, oats, distillers grain mix, pelleted soyhulls, alfalfa, and water ad libitum (Monteith et al., 2009, 2014a, 2019; Delger et al., 2011). All animals also had limited access to natural forage within the facilities. Facilities and procedures for research on captive deer followed guidelines outlined by the American Society of Mammalogists (Sikes, 2016) and were approved by the Institutional Animal Care 


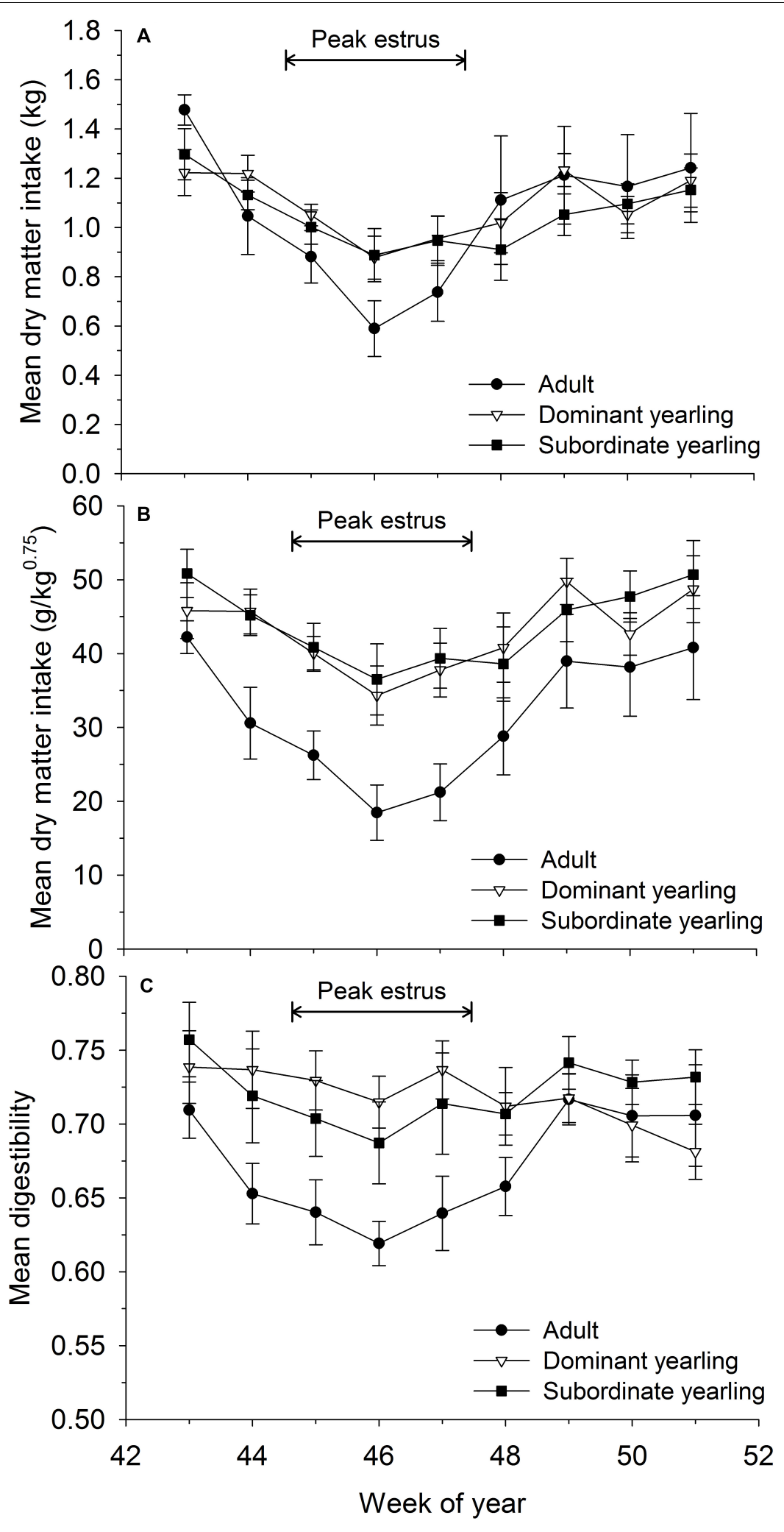

FIGURE 2 | Voluntary feed intake measured weekly as (A) absolute dry matter intake ( $\mathrm{kg} /$ day $\pm \mathrm{SE})$, (B) dry matter intake relative to metabolic body mass $\left(\mathrm{g} / \mathrm{kg}^{0.75} / \mathrm{day} \pm \mathrm{SE}\right)$, and (C) apparent digestibility (\% $\left.\pm \mathrm{SE}\right)$ for adult $(\geq 4.5$-years old; $n=12)$, dominant yearling (1.5-years old in absence of and adult male; $\left.n=11\right)$, and subordinate yearling (1.5-years old with adult male present; $n=9$ ) male white-tailed deer during 2006-2008 and 2010-2011, Brookings, SD, United States. Weeks correspond to mid-October through mid-December. Weeks of peak estrus represent dates when $86 \%$ of estimated conception events occurred. 
and Use Committee (Approval No. 09-020A) at South Dakota State University.

\section{Statistical Analyses}

We pooled data for corresponding weeks during the 5 years of the study to provide adequate sample size for statistical analyses. We used mean daily values of feed intake per week to represent a datum for each individual deer. We evaluated weekly trends in body mass and food intake by assessing differences in temporal patterns with their associated error among treatments (Johnson, 1999). Because we repeatedly monitored the same individuals through time within each year, we used repeated-measures analysis of variance with a heterogeneous autoregressive error structure and a lag of one to evaluate differences across weeks, treatment groups, and their interaction for feed intake, digestibility, and body mass. If the interaction term for treatment and week was not significant, we removed it from the model before examining effects of treatment and week on the response variable to avoid spurious results with a non-significant interaction term (Zar, 1999). To evaluate differences among treatment groups in measures of nutritional condition or serum parameters at specific instances in time (e.g., single sample events before rut), we used analysis of variance. We used Bonferroni corrections to maintain experiment-wise error rates to examine pair-wise comparisons when main effects were significant $(\alpha=0.05$; Zar, 1999). We also used simple least-squares regression to evaluate relationships between serum testosterone and food intake, and initial body mass with change in body mass over rut (Neter et al., 1996).

\section{RESULTS}

We monitored weekly patterns of forage intake and body mass of male white-tailed deer for 9 weeks during each autumn (i.e., mid-October to mid-December). We conducted our study during 5 years (2006-2008 and 2010-2011) and monitored 12 adult males, 11 dominant yearling males, and 9 subordinate yearlings.

Mean dry matter intake varied as a function of week $\left(F_{8,225}=7.86, P<0.001\right)$, with a $\sim 33 \%$ reduction in intake rates coinciding with peak estrus of females (Figure 2A). Although dry matter intake was generally higher for yearling than adult males (Figure 2A) and the treatment by week interaction approached significance $\left(F_{16,225}=1.58, P=0.075\right)$, all groups followed a similar pattern and were statistically similar $\left(F_{2,29}=0.05\right.$, $P=0.95)$. In contrast, mean dry matter intake relative to metabolic body mass differed among weeks $\left(F_{8}, 240=7.52\right.$, $P<0.001)$ and treatment groups $\left(F_{2,29}=5.65, P=0.008\right)$. The difference among treatment groups, however, was largely the result of adult males, which consumed markedly less food relative to metabolic body mass than yearling males (both $P<0.03)$. Subordinate and dominant yearlings followed similar patterns $(P=0.34)$. Mean $( \pm \mathrm{SE})$ dry matter intake relative to metabolic body mass of adult males during peak rut (week 46) was $52 \%$ that of yearling males (Figure 2B) and decreased from $42.2 \mathrm{~g} / \mathrm{kg}^{0.75} /$ day $( \pm 2.2)$ in mid-October to $18.5 \mathrm{~g} / \mathrm{kg}^{0.75} /$ day $( \pm 3.7)$ during the peak of the rut in mid-November (Figure 2B; week 46). Coincident with depressed intake rates, digestibility of consumed forage (as a measure of forage quality) varied by week $\left(F_{8,241}=5.06, P<0.001\right)$ and followed similar patterns to intake rates with reductions in digestibility during weeks with low food intake (Figure 2). Digestibility of diet consumed by adult males was consistently lower than yearling males throughout most of the autumn (Figure 2C), but not significantly so $\left(F_{2,29}=1.88\right.$, $P=0.17)$.

Body mass of males through autumn differed by treatment $\left(F_{2,29}=27.03, P<0.001\right)$, week $\left(F_{8,224}=37.44, P<0.001\right)$, and their interaction $\left(F_{16,224}=5.14, P<0.001\right)$. Adult males were consistently larger $(\sim 33 \%)$ than dominant and subordinate yearling males (both $P<0.001$ ), whereas dominant and subordinate yearlings were similar in size $(P=0.26)$. Weekly patterns of body mass were indicative of a general decline over autumn, which was most striking for adult males (Figure 3A). Weekly change in body mass varied as a function of treatment $\left(F_{2,29}=21.53, P<0.001\right)$ and week $\left(F_{7,21}=6.28, P<0.001\right)$. Adult males lost more body mass on a weekly basis than yearling males (both $P<0.001$ ), whereas change in body mass was similar between dominant and subordinate yearlings $(P=0.57)$. Adult

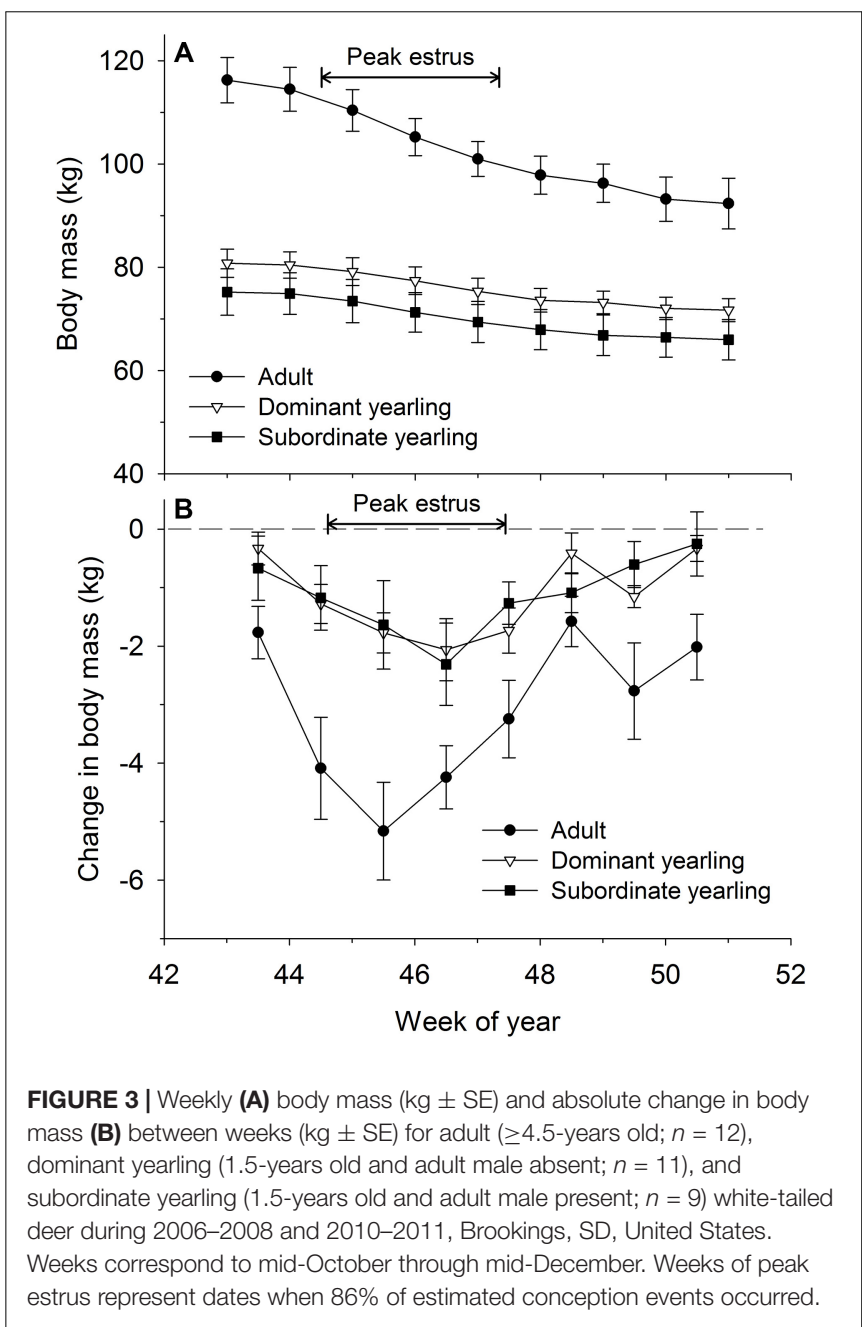


males consistently lost more body mass each week than yearling males, which was greatest during peak of the rut when adult males lost $>4 \mathrm{~kg}$ of body mass per week ( $\sim 4 \%$ decline per week). Loss of body mass during autumn differed among treatment groups $\left(F_{2,29}=30.09, P<0.001\right)$. Adult males lost $20 \%$ of body mass and yearlings lost $12 \%$ during autumn (both $P<0.001$ ), whereas mass loss by dominant and yearling males was nearly identical $(P=1.0$; Table 1). With all treatment groups combined, there was a strong linear relationship between initial body mass (mid-October) and change in body mass $\left(r^{2}=0.68, \beta=-0.31, P<0.001\right.$; through mid-December), with larger males losing more body mass over the autumn rut than smaller males (Figure 4, 5). At the onset of rut, adult males had slightly less IFBFat than yearling males $\left(F_{2,21}=3.00, P=0.071\right.$; Table 1$)$. Although treatment groups expended similar amounts of IFBFat during the rut $\left(F_{2,21}=2.52\right.$, $P=0.14$; Table 1), IFBFat decreased $31 \%$ (5.3 ppt) among adult males compared with a $22 \%(4.7 \mathrm{ppt})$ decline in yearling males.

Serum testosterone levels in mid-October differed between treatment groups $\left(F_{2,30}=19.86, P<0.001\right)$, which was mostly a function of elevated testosterone in adult males (both $P<0.001$ ) compared with both groups of yearling males, which were not different $(P=1.0)$. Mean $( \pm S E)$ serum testosterone levels were $18.6 \mathrm{ng} / \mathrm{ml}( \pm 2.75, n=10)$ for adult males, $5.65 \mathrm{ng} / \mathrm{ml}( \pm 1.56$, $n=11)$ for dominant yearlings, and $6.4 \mathrm{ng} / \mathrm{ml}( \pm 1.11, n=8)$ for subordinate yearlings. Differences among treatment groups in serum testosterone were diminished post-rut when all males exhibited low levels of testosterone (Figure 6). Although patterns seemed less consistent for yearling males (Figure 7), dry matter intake relative to metabolic body mass measured during the same week of serum collection in mid-October was related negatively to testosterone levels ( $\left.r^{2}=0.31, \beta=-0.75, P=0.001\right)$. Sample size was limited, but in contrast to testosterone, no patterns were apparent for serum cortisol concentrations either pre- or post-rut (all $P>0.10$; Figure 6), or among treatment groups (all $P>0.10$ ).

\section{DISCUSSION}

Reproductive expenditures by male ungulates can be substantial and may lead to future consequences for fitness (Stevenson and Bancroft, 1995; Mysterud et al., 2003, 2004, 2008a; Pelletier et al., 2006). The strong hierarchical social structure of male ungulates in autumn that is dominated largely by the presence of prime-aged males may confer benefits to young males throughout their life if the social dominance suppresses their rutting activity and forces them to conserve their somatic reserves. These ideas have appealing implications for management (Miller and Marchinton, 1995) and seem to have some empirical support (Mysterud et al., 2003), but had yet to be thoroughly tested. In contrast to the hypothesis that adult males suppress reproductive effort in young males during rut, food intake (Figure 2), hormone levels (Figure 6), and loss in somatic reserves (Figure 3) of yearling males was not affected by the presence of large, dominant males. Subordinate and dominant yearlings, and adult males exhibited pronounced hypophagia and mass loss in synchrony with the estrus cycle of females (Figure 2), but degree of hypophagia and mass loss was heightened in adult males. Indeed, reproductive effort as measured by reduction in food intake and associated mass loss occurred in a risk-sensitive manner, with larger males losing more mass during the rut compared with small males (i.e., yearling; Figure 4). Therefore, like females, male deer invested in reproduction in a way that capitalized on a reproductive opportunity, but presumably without overinvesting and compromising survival at a young age, and the opportunity to reproduce thereafter. In accordance with the old proverbial saying that cautions against risk taking and being satisfied with what one has now-one in the hand is worth two in the bush-males capitalized on a reproductive opportunity in hand while young. But, by doing so in a risk-sensitive manner, they still protected growth and survival that are necessary to secure future reproductive opportunities.

Young males expended reproductive effort (Figure 3), which is consistent with them taking advantage of a reproductive opportunity (Hogg and Forbes, 1997; Yoccoz et al., 2002; DeYoung et al., 2006; Foley et al., 2018). Despite the absence of an effect of adult males on reproductive expenditures of yearling males (Figure 3), lower reproductive effort by young males is likely a function of past selective pressures acting on post-rut survival and the continued need to grow to bolster reproductive success as adults. Such strategies suggest a natural regulating factor that inhibited overexertion in reproduction for a long-lived mammal that typically peaks in reproductive success after asymptotic body mass has been attained (DeYoung et al., 2006), especially considering that the bulk of reproductive expenditures in males must be associated with hypophagia as opposed to activity (Foley et al., 2018). Male white-tailed

TABLE 1 | Initial body mass and ingesta-free body fat (IFBFat) measured in mid-October, and the corresponding change in those variables over the autumn until mid-December for adult ( $\geq 4.5$-years old; $n=12$ ), dominant yearling (1.5-years old in absence of and adult male; $n=11$ ), and subordinate yearling (1.5-years old with adult male present; $n=9$ ) white-tailed deer during 2006-2008 and 2010-2011, Brookings, South Dakota, United States.

\begin{tabular}{|c|c|c|c|c|c|c|c|c|c|}
\hline \multirow[b]{2}{*}{ Treatment } & \multicolumn{3}{|c|}{ Adult } & \multicolumn{3}{|c|}{ Dominant yearling } & \multicolumn{3}{|c|}{ Subordinate yearling } \\
\hline & $\bar{x}$ & $S E$ & & $\bar{x}$ & SE & & $\bar{x}$ & $S E$ & \\
\hline Initial body mass (kg) & 116.24 & 4.40 & A & 80.78 & 2.72 & $\mathrm{~B}$ & 75.20 & 4.50 & $\mathrm{~B}$ \\
\hline Change body mass $(\mathrm{kg})$ & -23.50 & 1.96 & A & -9.07 & 0.85 & $\mathrm{~B}$ & -9.42 & 1.45 & $\mathrm{~B}$ \\
\hline Initial IFBFat (\%) & 17.28 & 0.69 & A & 20.20 & 1.25 & A & 22.23 & 1.77 & A \\
\hline Change IFBFat (pp) & -5.29 & 0.36 & $A$ & -5.60 & 0.69 & $A$ & -3.70 & 0.66 & $A$ \\
\hline
\end{tabular}

Different letters correspond to statistically significant differences between groups. 


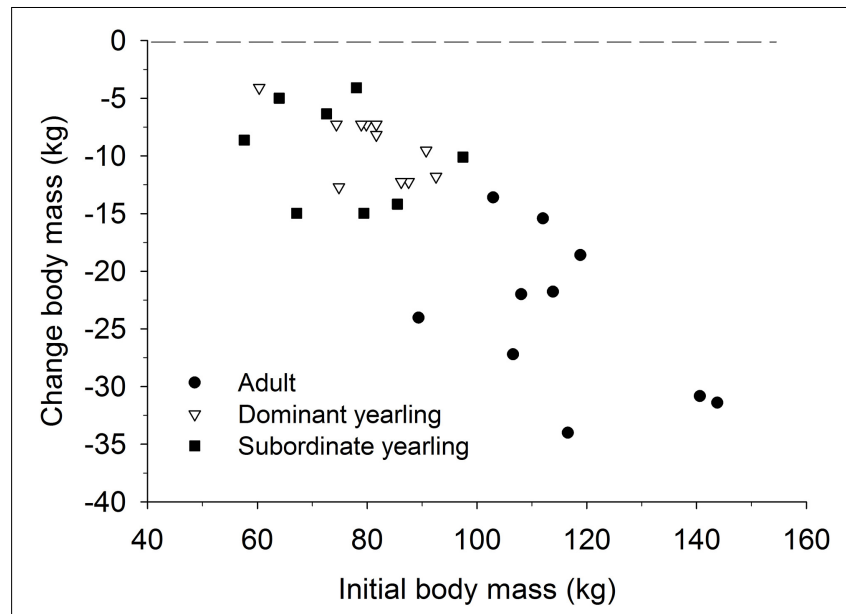

FIGURE 4 | Relationship between the cumulative change in body mass over the rut (mid-Oct to mid-Dec) and initial body mass $(\mathrm{kg})$ in mid-Oct for adult ( $\geq 4.5$-years old; $n=10$ ), dominant yearling (1.5-years old and adult male absent; $n=11)$, and subordinate yearling (1.5-years old and adult male present; $n=9$ ) white-tailed deer during 2006-2008 and 2010-2011, Brookings, SD, United States.

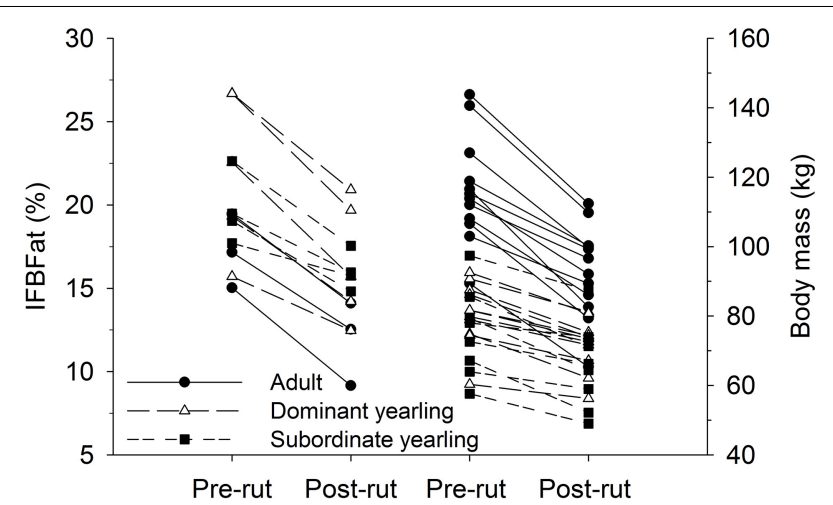

FIGURE 5 | Pair-wise comparisons of percent ingesta-free body fat (IFBFat) and body mass $(\mathrm{kg})$ measured immediately before the rut in mid-Oct and after the rut in mid-Dec for adult ( $\geq 4.5$-years old), dominant yearling (1.5-years old and adult male absent), and subordinate yearling (1.5-years old and adult male present) white-tailed deer during 2006-2008 and 2010-2011 (IFBFat only during 2010-2011), Brookings, SD, United States.

deer typically reach mature body size at 4.5 years-of-age and therefore, are rapidly growing at 1.5 years-of-age (Monteith et al., 2009). If resources are diverted from growth to reproduction, future competitive ability may be adversely affected if growth is attenuated. In most situations, reproductive success of young males is lower than all other age groups (Hogg, 1984; DeYoung et al., 2006; Jones et al., 2011). Consequently, expending substantial resources toward reproduction at an age when the fitness return is typically low, at the expense of future survival and reproduction is a poor choice for yearling males. Therefore, young males have apparently adopted a risk-sensitive reproductive strategy much like that displayed by many female ungulates (Bårdsen et al., 2010; Monteith et al., 2013b), wherein

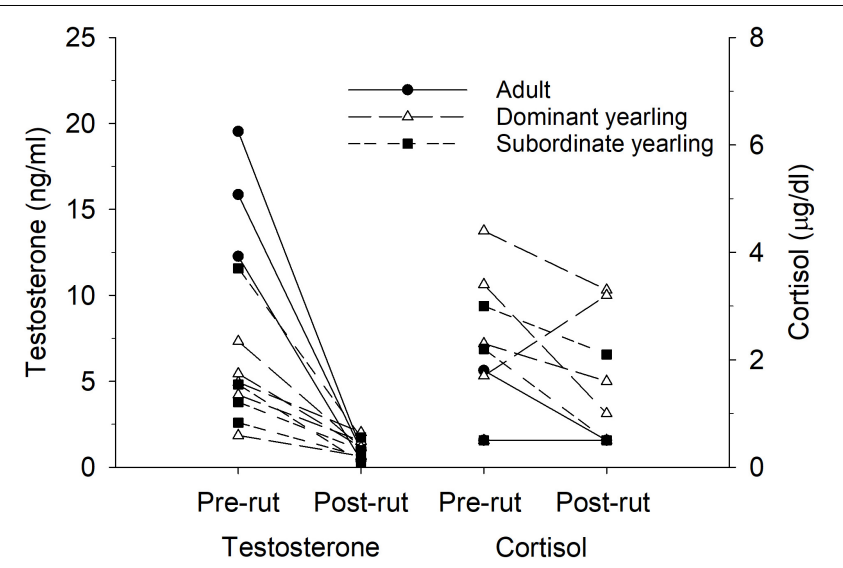

FIGURE 6 | Pair-wise comparisons of serum concentrations of testosterone $(\mathrm{ng} / \mathrm{ml})$ and cortisol $(\mu \mathrm{g} / \mathrm{dl})$ measured immediately before the rut in mid-Oct and after the rut in mid-Dec for adult ( $\geq 4$.5-years old; $n=3$ ), dominant yearling (1.5-years old and adult male absent; $n=5)$, and subordinate yearling (1.5-years old and adult male present; $n=4$ ) white-tailed deer during 2010-2011, Brookings, SD, United States.

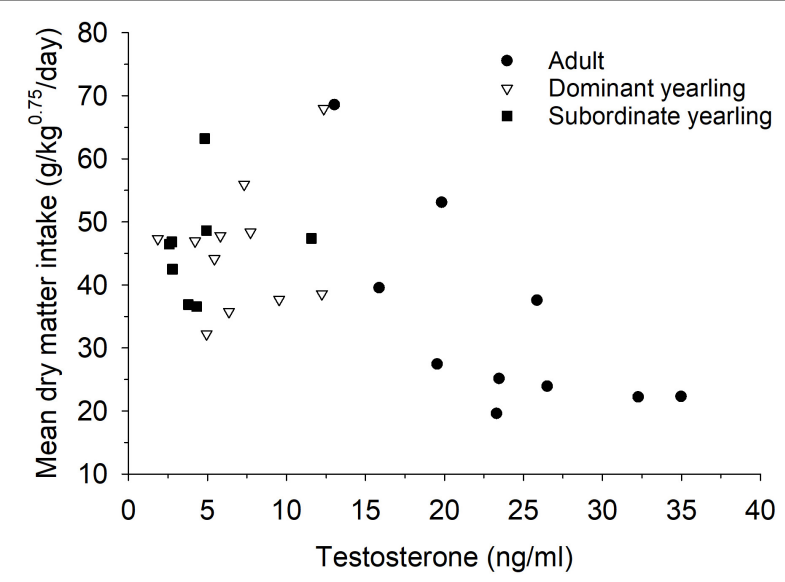

FIGURE 7 | Relationship between mean dry matter intake relative to metabolic body mass ( $\mathrm{g} / \mathrm{kg}^{0.75} /$ day) and serum testosterone $(\mathrm{ng} / \mathrm{ml})$ during week 43 for adult ( $\geq 4.5$-years old; $n=10$ ), dominant yearling (1.5-years old and adult male absent; $n=11$ ), and subordinate yearling (1.5-years old and adult male present; $n=8$ ) white-tailed deer during 2006-2008 and 2010-2011, Brookings, SD, United States.

allocation of resources to reproduction is sensitive to current nutritional state and the future risk to survival associated with depleting those reserves.

Male mammals can detect estrus in females by olfactory cues, and male behavior is commonly used by researchers as a tool to identify estrus in females (Komers et al., 1994a; Bowyer et al., 2007). It is important for males to time their reproductive effort to maximize the number of females that they can inseminate during the rut and make the most efficient use of effort expended toward reproduction. Prime-aged, dominant males often better match their reproductive effort with timing of estrus in females than do young, subordinate males (Preston et al., 2003; 
Mason et al., 2012). Adult male white-tailed deer closely timed their reproductive effort with estrus in females, with extreme hypophagia exhibited during the 3 weeks when $86 \%$ of the females used in the study ovulated (Figure 2). During those same 3 weeks, loss of body mass was greatest at $\sim 4 \%$ lost per week (Figure 3). Although yearling males exhibited comparable patterns in appetite suppression and mass loss, hypophagia was not as striking as adult males, and peak loss in body mass was delayed by 1 week (between weeks 46 and 47, compared with 45 and 46 in adult males). Similarly, young red deer (Cervus elaphus) delayed reproductive effort relative to adults (Mysterud et al., 2008b) and young male bison (Bison bison) tended females after estrus had already occurred (Komers et al., 1994b). Although adult males may have affected timing of reproductive effort in the subordinate yearling group, the presence of a similar pattern among dominant yearlings suggests that young males may be less experienced and less effective at timing reproductive effort with female estrus, or their behavior represents an adaptive advantage to wait until most adult males have expended their reserves during the rut.

In accordance with other work that measured reproductive effort of male ungulates by behavior or change in body mass (Yoccoz et al., 2002; Forsyth et al., 2005; Mainguy and Cote, 2008; Foley et al., 2018), reproductive expenditure by adult and yearling males differed markedly. Age-specific patterns of reproductive effort among males have indicated lower reproductive effort of young and old compared with prime-age males (Yoccoz et al., 2002; Mysterud et al., 2004; Forsyth et al., 2005; Pelletier et al., 2006). Greater reproductive effort by prime-aged males has been explained by the mating strategy-effort hypothesis, suggesting that effort should be highest in prime-aged males because they are better able to sustain the costs (Yoccoz et al., 2002; Mainguy and Cote, 2008). Nevertheless, such a pattern may similarly emerge as a result of risk-sensitive allocation of effort, wherein prime-age males that are finished growing should have greater reserves to allocate toward reproduction than young males that are actively growing or old males that are accumulating progressively less reserves as they age (McElligott et al., 2003). Accordingly, with rising population density, male red deer expended less reserves to reproduction because of reduced body mass going into the rut (Yoccoz et al., 2002). Likewise, old males commonly allocate less to reproduction (Yoccoz et al., 2002), which has been thought to be associated with senescence in reproduction, but we suspect is simply another example of allocation of effort to reproduction occurring in a risk-sensitive manner.

Regardless of the differences in timing and magnitude of feed intake between adult and yearling males, reproductive effort of male white-tailed deer was associated with a rapid and marked decline in voluntary feed intake (Figure 2), which was independent of the availability of food or their activity. Seasonal cycles of antler chronology, reproductive activity, and dominance are closely associated with fluctuations in reproductive hormones of male ungulates (Miller et al., 1987). Though our statistical power was limited given small sample size, testosterone levels of males at the initiation of the rut were markedly higher for adult than yearling males (Figure 6). As predicted, the mechanisms behind hypophagia during the rut seem to be closely tied to serum testosterone levels. Although we were unable to sample testosterone on a weekly basis, circulating testosterone had a negative influence on food intake relative to metabolic body mass for males during the same week (Figure 7). Exogenous administration of testosterone to male fallow deer (Dama dama) outside of the typical rut resulted in similar suppression in voluntary food intake to that observed during the natural rut (Newman et al., 1998). Therefore, lower levels of circulating testosterone by young males is the likely pathway by which a higher level of appetite is sustained during rut (Figure 2). Such a link between animal state and appetite or resource allocation may highlight exciting opportunities to help reveal the mechanistic pathways between animal state and resource allocation (Monteith et al., 2013b).

Although our results may not be entirely representative of a free-ranging situation where energy expenditures in locomotion may further magnify reproductive effort (Parker et al., 1984) and social interactions likely are more frequent (Mainguy and Cote, 2008), our study does indicate that energetic costs of reproduction for males likely are born out more through depression in appetite as opposed to just locomotive activity. Indeed, locomotive activity itself was insufficient to explain loss in body mass of white-tailed deer (Foley et al., 2018), and degree of rutting behavior was not associated with mass loss in fallow deer (McElligott et al., 2003). The voluntary hypophagia displayed by males during rut may serve to alleviate a demanding activity budget to allow more time to engage in activities that could promote reproductive success or energy savings and rest (Willisch and Ingold, 2007; Mainguy and Cote, 2008; Mysterud et al., 2008a). Consequently, if somatic costs of reproduction in male ungulates are largely a function of reduction in food intake, it could make interpretation of reproductive effort and associated costs more difficult via indirect measures of reproductive effort such as activity or movement. Because forage intake during rut appears to be under strong hormonal control (Figure 7), hypophagia and subsequent somatic costs may link strongly to nutritional state. This link may be a physiological pathway to maintain risk-sensitive allocation to reproduction among male ungulates.

The relative abundance and composition of males can have important effects on large ungulate populations, including effects on birth synchrony, timing, fecundity, and energy expenditures of females during the rut (Mysterud et al., 2002). Humans can influence the social landscape of male ungulates through hunting pressure (Jenks et al., 2002; LaSharr et al., 2019) and, in so doing, may alter the extent to which young animals invest or participate in reproduction. Because of a desire to harvest males with sizeable antlers or horns, certain hunting regimes may remove disproportionately more older than young individuals from the population (Monteith et al., 2013a; LaSharr et al., 2019). Harvest regimes that remove these older, likely dominant animals may allow more breeding opportunities for younger males. Increased opportunities to mate for young males has prompted concerns associated with greater expenditures during rut (Ditchkoff et al., 2001), which is consistent with observed increases in reproductive effort of young males in populations with a young male age structure or female biased sex ratio 
(Komers et al., 1994b; Mysterud et al., 2003). Nevertheless, tradeoffs associated with reproduction and survival in male ungulates is not a ubiquitous phenomenon (Mysterud et al., 2004; Festa-Bianchet, 2012), and our work indicates that even when presented with the opportunity to engage in reproduction at a young age without adult males, young males invest conservatively in reproduction.

Given expenditures of males during the rut, particularly those of adult males (Figure 4), management efforts focused at maintaining adequate habitat and moderating density dependence to improve pre-rut condition would help to maximize the resources available for growth and reproduction (Monteith et al., 2018). All males in our study were in good nutritional condition leading into rut. Although males in our study displayed risk-sensitive allocation, it is not known if adult males in poor nutritional condition at the onset of rut will compensate by increasing appetite to reduce somatic losses. Therefore, subsequent work should focus on understanding whether risk-sensitive reproductive tactics are displayed in free-ranging males where energetic expenditures are likely greater and social interactions potentially more frequent.

Differential evolutionary trajectories of the sexes are rooted in evolutionary theory (Darwin, 1871) and are profound for polygynous ungulates (Clutton-Brock, 1982; Bowyer, 2004). Rare, longitudinal data of direct measures of reproductive effort for a sexually dimorphic ungulate reveals more similarity in patterns of reproductive effort between males and females than previously appreciated. Unlike females, reproductive effort of males may be expended during a truncated window and manifest largely through a suppression in appetite rather than provisioning offspring. But like females, males displayed reproductive effort in a risk-sensitive manner wherein they invested in reproduction as a function of the resources available to them at the onset of rut. In accordance with life-history theory, young males conservatively invested in reproduction and prime-aged males invested heavily, but in a manner that should not have prompted a tradeoff in survival for reproductive effort. Indeed, under a risk-sensitive framework, reproductive costs should be masked or absent with respect to age or social rank. And instead, direct investment in reproduction for males may emanate largely from success in resource acquisition during the previous season and thus, the somatic reserves at hand.

\section{REFERENCES}

Andersson, M. (1994). Sexual Selection. Princeton, NJ: Princeton University.

Bårdsen, B.-J., Fauchald, P., Tveraa, T., Langeland, K., Yoccoz, N. G., and Ims, R. A. (2008). Experimental evidence of a risk-sensitive reproductive allocation in a long-lived mammal. Ecology 89, 829-837. doi: 10.1890/070414.1

Bårdsen, B.-J., Næss, M. W., Tveraa, T., Langeland, K., and Fauchald, P. (2014). Risk-sensitive reproductive allocation: fitness consequences of body mass losses in two contrasting environments. Ecol. Evol. 4, 1030-1038. doi: 10.1002/ece3. 1010

Bårdsen, B.-J., Tveraa, T., Fauchald, P., and Langeland, K. (2010). Observational evidence of risk-sensitive reproductive allocation in a long-lived mammal. Oecologia 162, 627-639. doi: 10.1007/s00442-009-1537-0

\section{DATA AVAILABILITY STATEMENT}

The datasets generated for this study are available on request to the corresponding author.

\section{ETHICS STATEMENT}

The animal study was reviewed and approved by the Institutional Animal Care and Use Committee (Approval No. 09-020A) at South Dakota State University.

\section{AUTHOR CONTRIBUTIONS}

KLM conceived of the idea. KLM, JJ, and KBM wrote the proposals to acquire financial support for the project. KLM and KBM conducted the study and analyzed the data. KLM and RJ led the writing of the manuscript, and all authors contributed to its completion.

\section{FUNDING}

Funding for this project was provided by National Fish and Wildlife Foundation through Quality Deer Management Association, Federal Aid to Wildlife Restoration Funds administered through South Dakota Department of Game, Fish and Parks (Study No. 7538, W-75-R), Berryman Institute, South Dakota Agricultural Experiment Station, and Joseph F. Nelson undergraduate research grant. We acknowledge support from Haub School of Environment and Natural Resources at University of Wyoming, and Department of Natural Resources at South Dakota State University.

\section{ACKNOWLEDGMENTS}

We thank L. Schmitz, J. Delger, J. Howell, E. Kjellsen, R. DeVore, A. Peterson, B. Borah, and J. Lindgren for help with captive deer studies. We also thank K. Adams for support and facilitating funding for the project. We thank M. Festa-Bianchet, F. GarciaGonzalez, and P. Krausman for critical feedback that helped improve our manuscript.

Berger, J., and Gompper, M. E. (1999). Sex ratios in extant ungulates: products of contemporary predation or past life histories? J. Mammal. 80, 1084-1113. doi: $10.2307 / 1383162$

Bergeron, P., Baeta, R., Pelletier, F., Reale, D., and Garant, D. (2011). Individual quality: tautology or biological reality? J. Anim. Ecol. 80, 361-364. doi: 10.1111/ j.1365-2656.2010.01770.x

Bleu, J., Gamelon, M., and Saether, B. E. (2016). Reproductive costs in terrestrial male vertebrates: insights from bird studies. Proc. R. Soc. B Biol. Sci. 283:20152600. doi: $10.1098 / \mathrm{rspb} .2015 .2600$

Bowyer, R. T. (2004). Sexual segregation in ruminants: definitions, hypotheses, and implications for conservation and management. J. Mammal. 85, 1039-1052. doi: 10.1644/bbl-002.1

Bowyer, R. T., Bleich, V. C., Manteca, X., Whiting, J. C., and Stewart, K. M. (2007). Sociality, mate choice, and timing of mating in American bison (bison bison): 
effects of large males. Ethology 113, 1048-1060. doi: 10.1111/j.1439-0310.2007. 01411.x

Charnov, E. L. (2002). Reproductive effort, offspring size and benefit-cost ratios in the classification of life histories. Evol. Ecol. Res. 4, 749-758.

Clutton-Brock, T. H. (1982). Red Deer: Behavior and Ecology of Two Sexes. Chicago, IL: The University of Chicago Press.

Clutton-Brock, T. H., Albon, S. D., and Guinness, F. E. (1989). Fitness costs of gestation and lactation in wild mammals. Nature 337, 260-262. doi: 10.1038/ 337260a0

Cole, L. C. (1954). The population consequences of life history phenomena. Q. Rev. Biol. 29, 103-137. doi: 10.1086/400074

Cook, R. C., Cook, J. G., Stephenson, T. R., Myers, W. L., Mccorquodale, S. M., Vales, D. J., et al. (2010). Revisions of rump fat and body scoring indices for deer, elk, and moose. J. Wildlife Manag. 74, 880-896. doi: 10.2193/ 2009-031

Cook, R. C., Stephenson, T. R., Myers, W. L., Cook, J. G., and Shipley, L. A. (2007). Validating predictive models of nutritional condition for mule deer. J. Wildlife Manag. 71, 1934-1943. doi: 10.2193/2006-262

Corlatti, L., Bassano, B., and Wright, J. (2014). Contrasting alternative hypotheses to explain rut-induced hypophagia in territorial male chamois. Ethology 120, 32-41. doi: 10.1111/eth.12177

Corlatti, L., Béthaz, S., Von Hardenberg, A., Bassano, B., Palme, R., and Lovari, S. (2012). Hormones, parasites and male mating tactics in alpine chamois: identifying the mechanisms of life history trade-offs. Anim. Behav. 84, 10611070. doi: 10.1016/j.anbehav.2012.08.005

Darwin, C. (1871). The Descent of Man, and Selection in Relation to Sex. London: Murray.

Delger, J. A., Monteith, K. L., Schmitz, L. E., and Jenks, J. A. (2011). Preference of white-tailed deer for corn hybrids and agricultural husbandry practices during the growing season. Hum. Wildlife Interact. 5, 32-46.

DeYoung, R. W., Demarais, S., Honeycutt, R. L., Gee, K. L., and Gonzales, R. A. (2006). Social dominance and male breeding success in captive white-tailed deer. Wildlife Soc. Bull. 34, 131-136. doi: 10.2193/0091-7648(2006)34[131: sdambs]2.0.co;2

Ditchkoff, S. S., Welch, E. R., Lochmiller, R. L., Masters, R. E., and Starry, W. R. (2001). Age-specific causes of mortality among male white-tailed deer support mate-competition theory. J. Wildlife Manag. 65, 552-559.

Festa-Bianchet, M. (2012). The cost of trying: weak interspecific correlations among life-history components in male ungulates. Can. J. Zool. 90, 1072-1085. doi: $10.1139 / \mathrm{z} 2012-080$

Foley, A. M., Hewitt, D. G., Deyoung, R. W., Schnupp, M. J., Hellickson, M. W., and Lockwood, M. A. (2018). Reproductive effort and success of males in scramble-competition polygyny: evidence for trade-offs between foraging and mate search. J. Anim. Ecol. 87, 1600-1614. doi: 10.1111/1365-2656.12893

Forsyth, D. M., Duncan, R. P., Tustin, K. G., and Gaillard, J.-M. (2005). A substantial energetic cost to male reproduction in a sexually dimorphic ungulate. Ecology 86, 2154-2163. doi: 10.1890/03-0738

Geist, V. (1971). Mountain Sheep. Chicago, IL: University of Chicago Press.

Hogg, J. T. (1984). Mating in bighorn sheep: multiple creative male strategies. Science 225, 526-529. doi: 10.1126/science.6539948

Hogg, J. T., and Forbes, S. H. (1997). Mating in bighorn sheep: frequent male reproduction via a high-risk "unconventional" tactic. Behav. Ecol. Sociobiol. 41, 33-48. doi: 10.1007/s002650050361

Jenks, J. A., Smith, W. P., and Deperno, C. S. (2002). Maximum sustained yield harvest versus trophy management. J. Wildlife Manag. 66, 528-535.

Johnson, D. H. (1999). The insignificance of statistical significance testing. J. Wildlife Manag. 63, 763-772.

Jones, P. D., Strickland, B. K., Demarais, S., and Deyoung, R. W. (2011). Inconsistent association of male body mass with breeding success in captive white-tailed deer. J. Mammal. 92, 527-533. doi: 10.1644/10-mamm-a-294.1

Jönsson, K. I. (1997). Capital and income breeding as alternative tactics of resource use in reproduction. Oikos 78, 57-66.

Komers, P. E., Messier, F., Flood, P. F., and Gates, C. C. (1994a). Reproductivebehavior of male wood bison in relation to progesterone level in females. J. Mammal. 75, 757-765. doi: 10.2307/1382527

Komers, P. E., Messier, F., and Gates, C. C. (1994b). Plasticity of reproductivebehavior in wood bison bulls - when subadults are given a chance. Ethol. Ecol. Evol. 6, 313-330. doi: 10.1080/08927014.1994.9522984
Kozłowski, J. (1992). Optimal allocation of resources to growth and reproduction: implications for age and size at maturity. Trends Ecolo. Evol. 7, 15-19. doi: 10.1016/0169-5347(92)90192-e

Kruuk, L. E. B., Slate, J., Pemberton, J. M., Brotherstone, S., Guinness, F., and Clutton-Brock, T. (2002). Antler size in red deer: heritability and selection but no evolution. Evolution 56, 1683-1695. doi: 10.1111/j.0014-3820.2002.tb 01480.x

LaSharr, T. N., Long, R. A., Heffelfinger, J. R., Bleich, V. C., Krausman, P. R., Bowyer, R. T., et al. (2019). Hunting and mountain sheep: do current harvest practices affect horn growth? Evol. Appl. 12, 1823-1836. doi: 10.1111/eva. 12841

Mainguy, J., and Cote, S. D. (2008). Age- and state-dependent reproductive effort in male mountain goats, Oreamnos americanus. Behav. Ecol. Sociobiol. 62, 935-943. doi: 10.1007/s00265-007-0517-9

Martin, J. G. A., and Festa-Bianchet, M. (2010). Bighorn ewes transfer the costs of reproduction to their lambs. Am. Nat. 176, 414-423. doi: 10.1086/656267

Mason, T. H., Stephens, P. A., Willis, S. G., Chirichella, R., Apollonio, M., and Richards, S. A. (2012). Intraseasonal variation in reproductive effort: young males finish last. Am. Nat. 180, 823-830. doi: 10.1086/668082

Mautz, W. W., Silver, H., Holter, J. B., Hayes, H. H., and Urban, W. E. (1976). Digestibility and related nutritional data for 7 northern deer browse species. J. Wildlife Manag. 40, 630-638.

McElligott, A. G., Naulty, F., Clarke, W. V., and Hayden, T. J. (2003). The somatic cost of reproduction: what determines reproductive effort in prime-aged fallow bucks? Evol. Ecol. Res. 5, 1239-1250.

Miller, K. V., and Marchinton, R. L. (1995). Quality Whitetails: The Why and How of Quality Deer Management. Mechanicsburg, PA: Stackpole Books.

Miller, K. V., Marchinton, R. L., Forand, K. J., and Johansen, K. L. (1987). Dominance, testosterone levels, and scraping activity in a captive herd of white-tailed deer. J. Mammal. 68, 812-817. doi: 10.2307/1381558

Miquelle, D. (1990). Why don't bull moose eat during the rut? Behav. Ecol. Sociobiol. 27, 145-151. doi: 10.1007/bf00168458

Monteith, K. B., Monteith, K. L., Bowyer, R. T., Leslie, D. M., and Jenks, J. A. (2014a). Reproductive effects on fecal nitrogen as an index of diet quality: an experimental assessment. J. Mammal. 95, 301-310. doi: 10.1644/12-mamm-a306.1

Monteith, K. L., Bleich, V. C., Stephenson, T. R., Pierce, B. M., Conner, M. M., Kie, J. G., et al. (2014b). Life-history characteristics of mule deer: effects of nutrition in a variable environment. Wildlife Monogr. 186, 1-62. doi: 10.1002/wmon. 1011

Monteith, K. B., Monteith, K. L., and Jenks, J. A. (2019). Condensed tannins as a deterrent to crop depredation by white-tailed deer: effects of concentration and learning. Wildlife Soc. Bull. 43, 693-700. doi: 10.1002/wsb.1028

Monteith, K. L., Long, R. A., Bleich, V. C., Heffelfinger, J. R., Krausman, P. R., and Bowyer, R. T. (2013a). Effects of harvest, culture, and climate on trends in size of horn-like structures in trophy ungulates. Wildlife Monogr. 183, 1-28. doi: 10.1002/wmon.1007

Monteith, K. L., Stephenson, T. R., Bleich, V. C., Conner, M. M., Pierce, B. M., and Bowyer, R. T. (2013b). Risk-sensitive allocation in seasonal dynamics of fat and protein reserves in a long-lived mammal. J. Anim. Ecol. 82, 377-388. doi: 10.1111/1365-2656.12016

Monteith, K. L., Long, R. A., Stephenson, T. R., Bleich, V. C., Bowyer, R. T., and Lasharr, T. N. (2018). Horn size and nutrition in mountain sheep: can ewe handle the truth? J. Wildlife Manag. 82, 67-84. doi: 10.1002/jwmg.21338

Monteith, K. L., Monteith, K. B., Delger, J. A., Schmitz, L. E., Brinkman, T. J., Deperno, C. S., et al. (2012). Immobilization of white-tailed deer with telazol, ketamine, and xylazine, and evaluation of antagonists. J. Wildlife Manag. 76, 1412-1419. doi: 10.1002/jwmg.383

Monteith, K. L., Schmitz, L. E., Jenks, J. A., Delger, J. A., and Bowyer, R. T. (2009) Growth of male white-tailed deer: consequences of maternal effects. J. Mammal. 90, 651-660. doi: 10.1644/08-mamm-a-191r1.1

Mysterud, A., Bonenfant, C., Loe, L. E., Langvatn, R., Yoccoz, N. G., and Stenseth, N. C. (2008a). Age-specific feeding cessation in male red deer during rut. J. Zool. 275, 407-412. doi: 10.1111/j.1469-7998.2008.00453.x

Mysterud, A., Bonenfant, C., Loe, L. E., Langvatn, R., Yoccoz, N. G., and Stenseth, N. C. (2008b). The timing of male reproductive effort relative to female ovulation in a capital breeder. J. Anim. Ecol. 77, 469-477. doi: 10.1111/j.13652656.2008.01365.x 
Mysterud, A., Coulson, T., and Stenseth, N. C. (2002). The role of males in the dynamics of ungulate populations. J. Anim. Ecol. 71, 907-915. doi: 10.1046/j. 1365-2656.2002.00655.x

Mysterud, A., Holand, O., Roed, K. H., Gjostein, H., Kumpula, J., and Nieminen, M. (2003). Effects of age, density and sex ratio on reproductive effort in male reindeer (Rangifer tarandus). J. Zool. 261, 341-344. doi: 10.1017/ s0952836903004114

Mysterud, A., Langvatn, R., and Stenseth, N. C. (2004). Patterns of reproductive effort in male ungulates. J. Zool. 264, 209-215. doi: 10.1017/s0952836904005618

Neter, J., Kutner, M. H., Nachtsheim, C. J., and Wasserman, W. (1996). Applied Linear Statistical Models. Boston, MA: WCB McGraw-Hill.

Newman, R. E., Mcconnell, S. J., Weston, R. H., Reeves, M., Bernasconi, C., Baker, P. J., et al. (1998). The relationship between plasma testosterone concentrations and the seasonal variation in voluntary feed intake in fallow bucks (dama dama). J. Agric. Sci. 130, 357-366. doi: 10.1017/s0021859698005279

Panzacchi, M., Herfindal, I., Linnell, J. D. C., Odden, M., Odden, J., and Andersen, R. (2010). Trade-offs between maternal foraging and fawn predation risk in an income breeder. Behav. Ecol. Sociobiol. 64, 1267-1278. doi: 10.1007/s00265010-0941-0

Parker, K. L., Robbins, C. T., and Hanley, T. A. (1984). Energy expenditures for locomotion by mule deer and elk. J. Wildlife Manag. 48, 474-488.

Pelletier, F., Bauman, J., and Festa-Bianchet, M. (2003). Fecal testosterone in bighorn sheep (Ovis canadensis): behavioural and endocrine correlates. Can. J. Zool. 81, 1678-1684. doi: 10.1139/z03-156

Pelletier, F., Hogg, J. T., and Festa-Bianchet, M. (2006). Male mating effort in a polygynous ungulate. Behav. Ecol. Sociobiol. 60, 645-654. doi: 10.1007/s00265006-0208-y

Preston, B. T., Stevenson, I. R., and Wilson, K. (2003). Soay rams target reproductive activity towards promiscuous females' optimal insemination period. Proc. R. Soc. B 270, 2073-2078. doi: 10.1098/rspb.2003.2465

Robbins, C. T. (1983). Wildlife Feeding and Nutrition. Orlando, FL: Academic Press.

Ryg, M. (1982). Seasonal changes in weight gain, growth hormone, and thyroid hormones in intact and castrated male moose (Alces alces alces). Can. J. Zool. 60, 2941-2946. doi: 10.1139/z82-371

Shallow, J. R. T., Hurley, M. A., Monteith, K. L., and Bowyer, R. T. (2015). Cascading effects of habitat on maternal condition and life-history characteristics of neonatal mule deer. J. Mammal. 96, 194-205. doi: 10.1093/ jmammal/gyu024
Sikes, R. S. (2016). 2016 guidelines of the American society of mammalogists for the use of wild mammals in research and education. J. Mammal. 97, 663-688. doi: 10.1093/jmammal/gyw078

Spuhler, W., Lytle, W. F., and Moe, D. (1971). Climate of South Dakota. South Dakota State Univer. Agric. Exper. Sta. Bull. 582:30.

Stearns, S. C. (1992). The Evolution of Life-Histories. Oxford: Oxford University Press.

Stephenson, T. R., Bleich, V. C., Pierce, B. M., and Mulcahy, G. P. (2002). Validation of mule deer body composition using in vivo and post-mortem indices of nutritional condition. Wildlife Soc. Bull. 30, 557-564.

Stevenson, I. R., and Bancroft, D. R. (1995). Fluctuating trade-offs favour precocial maturity in male soay sheep. Proc. R. Soc. B Biol. Sci. 262, 267-275. doi: 10.1098/rspb.1995.0205

Tollefson, T. N., Shipley, L. A., Myers, W. L., Keisler, D. H., and Dasgupta, N. (2010). Influence of summer and autumn nutrition on body condition and reproduction in lactating mule deer. J. Wildlife Manag. 74, 974-986. doi: 10.2193/2008-529

Townsend, T. W., and Bailey, E. D. (1981). Effects of age, sex and weight on social rank in penned white-tailed deer. Am. Midland Nat. 106, 92-101.

Willisch, C. S., and Ingold, P. (2007). Feeding or resting? The strategy of rutting male alpine chamois. Ethology 113, 97-104.

Willisch, C. S., and Neuhaus, P. (2010). Social dominance and conflict reduction in rutting male alpine ibex, capra ibex. Behav. Ecol. 21, 372-380. doi: 10.1093/ beheco/arp200

Yoccoz, N. G., Mysterud, A., Langvatn, R., and Stenseth, N. C. (2002). Age- and density-dependent reproductive effort in male red deer. Proc. R. Soc. B Biol. Sci. 269, 1523-1528. doi: 10.1098/rspb.2002.2047

Zar, J. H. (1999). Biostatistical Analysis. Upper Saddle River, NJ: Prentice Hall.

Conflict of Interest: The authors declare that the research was conducted in the absence of any commercial or financial relationships that could be construed as a potential conflict of interest.

Copyright (C) 2020 Monteith, Monteith, Jenks and Jakopak. This is an open-access article distributed under the terms of the Creative Commons Attribution License (CC BY). The use, distribution or reproduction in other forums is permitted, provided the original author(s) and the copyright owner(s) are credited and that the original publication in this journal is cited, in accordance with accepted academic practice. No use, distribution or reproduction is permitted which does not comply with these terms. 